\title{
Technical Note: How accurate can stalagmite formation temperatures be determined using vapour bubble radius measurements in fluid inclusions?
}

\author{
F. Spadin ${ }^{1}$, D. Marti ${ }^{1,3}$, R. Hidalgo-Staub ${ }^{1}$, J. Rička ${ }^{1}$, D. Fleitmann ${ }^{2}$, and M. Frenz ${ }^{1}$ \\ ${ }^{1}$ Institute of Applied Physics, University of Bern, Sidlerstrasse 5, 3012 Bern, Switzerland \\ ${ }^{2}$ Centre for Past Climate Change, University of Reading, Whiteknights, Reading, UK \\ ${ }^{3}$ Department of Photonics Engineering, Technical University of Denmark, Frederiksborgvej 399, 4000 Roskilde, Denmark
}

Correspondence to: M. Frenz (frenz@iap.unibe.ch)

Received: 5 August 2014 - Published in Clim. Past Discuss.: 9 September 2014

Revised: 15 May 2015 - Accepted: 28 May 2015 - Published: 17 June 2015

\begin{abstract}
Stalagmites are natural archives containing detailed information on continental climate variability of the past. Microthermometric measurements of fluid inclusion homogenisation temperatures allow determination of stalagmite formation temperatures by measuring the radius of stable laser-induced vapour bubbles inside the inclusions. A reliable method for precisely measuring the radius of vapour bubbles is presented. The method is applied to stalagmite samples for which the formation temperature is known. An assessment of the bubble radius measurement accuracy and how this error influences the uncertainty in determining the formation temperature is provided. We demonstrate that the nominal homogenisation temperature of a single inclusion can be determined with an accuracy of $\pm 0.25^{\circ} \mathrm{C}$, if the volume of the inclusion is larger than $10^{5} \mu \mathrm{m}^{3}$. With this method, we could measure in a proof-of-principle investigation that the formation temperature of $10-20 \mathrm{yr}$ old inclusions in a stalagmite taken from the Milandre cave is $9.87 \pm 0.80^{\circ} \mathrm{C}$, while the mean annual surface temperature, that in the case of the Milandre cave correlates well with the cave temperature, was $9.6 \pm 0.15^{\circ} \mathrm{C}$, calculated from actual measurements at that time, showing a very good agreement. Formation temperatures of inclusions formed during the last $450 \mathrm{yr}$ are found in a temperature range between 8.4 and $9.6^{\circ} \mathrm{C}$, which corresponds to the calculated average surface temperature. Paleotemperatures can thus be determined within $\pm 1.0^{\circ} \mathrm{C}$.
\end{abstract}

\section{Introduction}

In recent years, stalagmites have gained growing interest in palaeoclimate research since they can provide long (up to several hundred thousand years), detailed and precisely dated records of past climate variability. In many cases cave air temperature is stable throughout the year and is closely related to the mean annual air temperature above the cave (McDermott, 2004; Fairchild et al., 2006). Assuming that the stalagmite formation temperature equals the cave air temperature, stalagmites can deliver well-dated and highly resolved palaeotemperature records.

Until now, palaeoclimate information from stalagmites has mainly been obtained from stable isotope measurements of speleothem calcite $\left(\delta^{18} \mathrm{O}\right.$ and $\left.\delta^{13} \mathrm{C}\right)$, annual band thickness and trace element contents (Fairchild and Treble, 2009). These climate proxies can deliver qualitative records of climate variability, but a quantitative interpretation of the data still remains difficult. Uncertainties associated with the interpretation of the most widely used climate proxy, the $\delta^{18} \mathrm{O}$ signal, are caused by the lack of knowledge of the exact cave temperature. Furthermore, the $\delta^{18} \mathrm{O}$ signal can be influenced by other climatic factors such as precipitation and moisture source as well as by environmental factors in the epikarst and the cave. Thus, an independent temperature proxy would form the basis for a quantitative interpretation of the highresolution $\delta^{18} \mathrm{O}$ isotope records.

Several quantitative temperature proxies have been used to determine stalagmite formation temperatures. Among these 
are "clumped isotopes" (Ghosh et al., 2006; Affek et al., 2008), $\delta D$ and $\delta^{18} \mathrm{O}$ signals (McGarry et al., 2004; Zhang et al., 2008) and noble gas concentrations of speleothem fluid inclusion water (Kluge et al., 2008; Scheidegger et al., 2010).

Recently, the fluid inclusion liquid vapour homogenisation temperature $T_{\mathrm{h}}$ has been used as an additional proxy for determining cave air temperatures (Krüger et al., 2011). Fluid inclusions in stalagmites are primary, which means that they are formed during crystal growth and thus contain remnants of the calcite supplying drip water (Kendall and Broughton, 1978). As stalagmites grow under atmospheric pressure conditions, the density of the encapsulated water depends solely on the stalagmite formation temperature and can thus be determined from $T_{\mathrm{h}}$ measurements of fluid inclusions.

However, fluid inclusions from low-temperature environments are usually in a monophase liquid state. Upon being cooled below their formation temperature down to a temperature of maximum tension, they remain in a long-lived metastable state inhibiting a spontaneous nucleation of the vapour phase. To overcome this metastability, we then use ultra-short laser pulses to induce vapour bubble nucleation in the metastable liquid, thus creating a stable two-phase inclusion appropriate for subsequent measurements of the liquid vapour homogenisation temperature $T_{\mathrm{h}}$ (Krüger et al., 2007, 2011).

For a notional stalagmite fluid inclusion of infinite volume, the experimentally observed (measured) homogenisation temperature $T_{\mathrm{h} \text { obs }}$ is equal to the liquid-vapour equilibrium temperature at ambient pressure. Therefore, we call this temperature the nominal homogenisation temperature $T_{\mathrm{h} \infty}$. It is equal to the stalagmite formation temperature $T_{\mathrm{f}}$, provided that the inclusion has preserved its original fluid density. In an inclusion of finite volume, however, $T_{\mathrm{h}}$ obs may differ significantly from $T_{\mathrm{h} \infty}$ due to the effect of surface tension, working towards a minimisation of the liquidvapour interface between the bulk liquid and the vapour bubble. Upon heating of the inclusion, the surface tension increases with decreasing vapour bubble radius, eventually getting strong enough to force the vapour bubble to collapse at a temperature well below $T_{\mathrm{h} \infty}$, even though after the collapse the bulk liquid will be in a monophase liquid state under negative pressure (Fall et al., 2009; Marti et al., 2012). Although $T_{\mathrm{h} \infty}$ of a fluid inclusion cannot be measured directly, it can be determined using the thermodynamic model proposed by Marti et al. (2012). The model describes the effect of surface tension on liquid-vapour equilibria in isochoric pure water systems. It can be applied to approximate the $p-V-T$ (pressure, volume, temperature) properties of drip water encapsulated in stalagmite fluid inclusions if the size of the vapour bubble is known for at least two temperature values.

The aim of this study was to evaluate the accuracy of this new temperature proxy, both for determining $T_{\mathrm{h} \infty}$ of a single fluid inclusion and for determining the formation temperature of a stalagmite growth band. For these purposes, we introduce an accurate and reliable method for measuring the bubble radius inside the fluid inclusion. Based on the thermodynamic model, we will show how the accuracy of $T_{\mathrm{h} \infty}$ is influenced by a measuring error in the vapour bubble radius and what error in the radius measurement is tolerable to achieve a precision of $\pm 0.25^{\circ} \mathrm{C}$ in the determination of the stalagmite formation temperature $T_{\mathrm{f}}$. The theoretical values are compared to experiments performed on fluid inclusions from actively growing stalagmites from the Milandre cave in Switzerland.

\section{Theoretical background}

Equation (1) sets the volume $V$ and the formation (bulk) density $\varrho_{\mathrm{f}}$ of a fluid inclusion in relation to the radius of vapour bubbles at a given temperature $r(T)$. The formation density $\varrho_{\mathrm{f}}$ equals the saturation density of liquid water at the formation temperature $T_{\mathrm{f}}$, i.e. $\varrho_{\mathrm{f}}=\varrho_{\mathrm{L}}^{\mathrm{s}}\left(T_{\mathrm{f}}\right)$. Due to the low formation temperature of stalagmites, the volume of the vapour bubble is small compared to the total volume of the inclusion and the shape of the bubble can be assumed to be spherical. Note that Eq. (1) is only valid for an isochoric system:

$\frac{\varrho_{\mathrm{f}}}{\varrho_{\mathrm{L}}^{\mathrm{S}}(T)} \approx\left[1-\frac{2 \sigma(T)}{r(T)} \kappa_{\mathrm{L}}(T)\right]\left[1-\frac{4 \pi r(T)^{3}}{3 V}.\right]$

$\varrho_{\mathrm{L}}^{\mathrm{s}}(T)$ is the saturation density of liquid water, $\sigma(T)$ is the surface tension and $\kappa_{\mathrm{L}}(T)$ is the isothermal compressibility of liquid water. The values of these temperature dependent variables can be derived from the IAPWS-95 formulation (Wagner and Pruss, 2002). In the isochoric system, the two unknown variables $\varrho_{\mathrm{f}}$, the bulk density that serves as a measure for $T_{\mathrm{h} \infty}\left(=T_{\mathrm{f}}\right)$ and $V$, the volume of the fluid inclusion, are constant, whereas the radius $r$ of the vapour bubble that varies with temperature $T$ is a measurable quantity. Equation (1) is a good approximation if the density of the liquid phase is much higher than the density of the gaseous phase, i.e. far away from the critical point. To apply Eq. (1) to fluid inclusions in stalagmites, we additionally must take into account the deviation of fluid inclusions from the isochoric system, i.e. the temperature dependent volume change of the host calcite. Equation (1) then reads

$\frac{\varrho_{\mathrm{f}}}{\varrho_{\mathrm{L}}^{\mathrm{S}}(T)} \frac{V\left(T_{\mathrm{h} \infty}\right)}{V(T)} \approx\left[1-\frac{2 \sigma(T)}{r(T)} \kappa_{\mathrm{L}}(T)\right]\left[1-\frac{4 \pi r(T)^{3}}{3 V(T)}\right]$

with

$V(T)=V\left(T_{\mathrm{h} \infty}\right)+\alpha\left(T_{\mathrm{h} \infty}-T\right)$,

where $V\left(T_{\mathrm{h} \infty}\right)$ is the volume of the inclusion at the nominal homogenisation temperature and $\alpha$ denotes the thermal expansion coefficient of calcite derived from an extrapolation of experimental data of Rao et al. (1968). To solve Eq. (2) for the two unknown parameters $\varrho_{\mathrm{f}}\left(\equiv T_{\mathrm{h} \infty}=T_{\mathrm{f}}\right)$ and $V\left(T_{\mathrm{h} \infty}\right)$, we need at least two measurements of the vapour bubble radius at two different temperatures that can be chosen arbitrarily. Marti et al. (2012) suggested measuring the maximum bubble radius, which in a pure calcite host is reached 
at $5.1{ }^{\circ} \mathrm{C}$ (Marti et al., 2009), and the minimum (zero) radius that is reached at $T_{\mathrm{h} \text { obs. }}$. The second radius measurement is trivial, yet Marti et al. (2012) pointed out that the thermodynamic model defines $T_{\mathrm{h} \text { obs }}$ only within a certain range since the two-phase system passes through a metastable field upon heating; in this study, we assume $T_{\mathrm{h} \text { obs }}$ to coincide with the thermodynamic instability limit of the two-phase system.

\section{Experimental methods}

\subsection{Samples and preparation}

We analysed fluid inclusions in two stalagmites from the Milandre cave in Switzerland $\left(47^{\circ} 29^{\prime} \mathrm{N}, 07^{\circ} 01^{\prime} \mathrm{E}\right)$, both with columnar calcite fabrics. The two stalagmites, M1 and M2, were located approximately $50 \mathrm{~m}$ apart and actively growing when collected in 2007. The studied top layer sections do not show any signs (e.g. dust layers) of discontinuities (Fig. 1). A total of five uranium series dates for stalagmite M2 suggest a slow and remarkably constant growth rate of between 0.013 and $0.017 \mathrm{~mm} \mathrm{yr}^{-1}$ over the last $14300 \mathrm{yr}$ (Häuselmann et al., 2015). The lack of uranium series dates for stalagmite M1 makes it difficult to calculate precise growth rates. However, since the shape and calcite textures of stalagmite M1 are very similar to those of M2 (see Fig. 1 and Fig. 2), we assume that the growth rates of both stalagmites are very similar, also because both samples were formed under the same growth conditions (drip rate, drip height, temperature, ventilation and $\left.p\left(\mathrm{CO}_{2}\right)\right)$. The temperature in the Milandre cave was monitored during the year 2008 using temperature loggers at the two stalagmite sites yielding mean cave air temperatures of $9.59^{\circ} \mathrm{C}(\mathrm{M} 1)$ and $9.56{ }^{\circ} \mathrm{C}(\mathrm{M} 2)$. The temperature in the cave was found to be stable within $\pm 0.15^{\circ} \mathrm{C}$ throughout the year (Schmassmann, 2010).

- Stalagmite M1 is $37 \mathrm{~cm}$ long and fed by a soda straw $142 \mathrm{~cm}$ above, with an average drip period of $5^{\prime} 45^{\prime \prime}$. It contains numerous sealed fluid inclusions at the very top (Fig. 2a). Only these inclusions were used for investigating the accuracy with which the homogenisation temperature $T_{\mathrm{h} \infty}$ can be determined.

- Stalagmite M2 is $27 \mathrm{~cm}$ long and fed by a soda straw $155 \mathrm{~cm}$ above with an average drip period of $6^{\prime} 30^{\prime \prime}$. In the top part of the stalagmite several growth bands are visible, containing large fluid inclusions (see Fig. 2b). Fluid inclusions in the most recent growth band are still open, i.e. they have not been sealed off by calcite overgrowth. Figure $2 b$ shows the four top major growth bands with numerous fluid inclusions which were used to determine the average cave temperature during the last $450 \mathrm{yr}$.

We assume that the cave air temperature at the time a fluid inclusion was sealed by calcite overgrowth determines the density of the enclosed fluid. Therefore, the age of a single

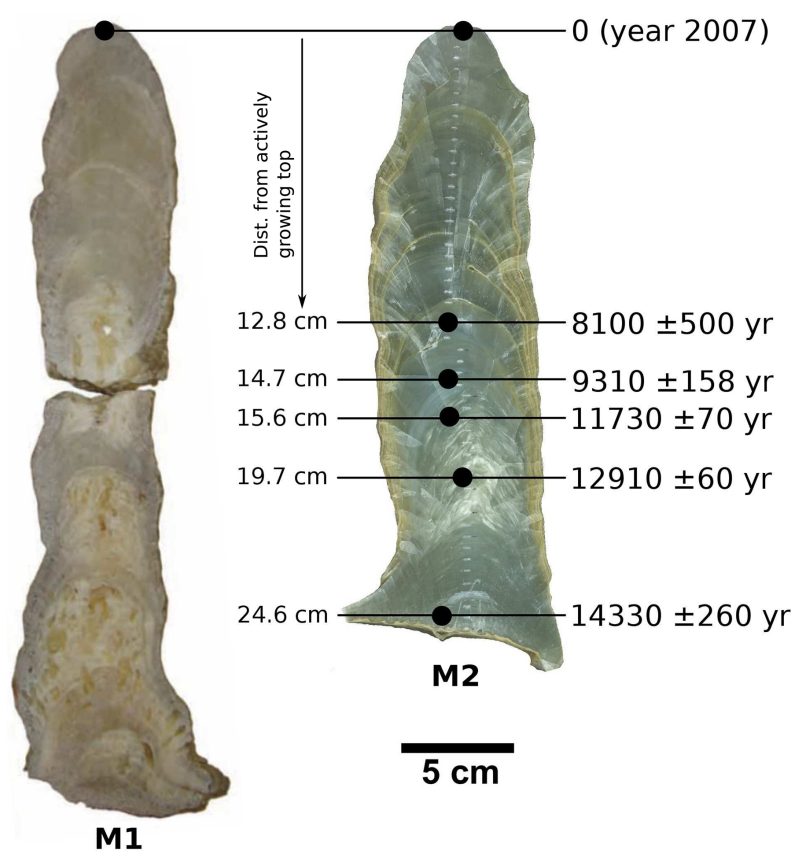

Figure 1. Photographs (cross sections) of the stalagmites M1 and M2 showing the locations of the U/Th dated layers.

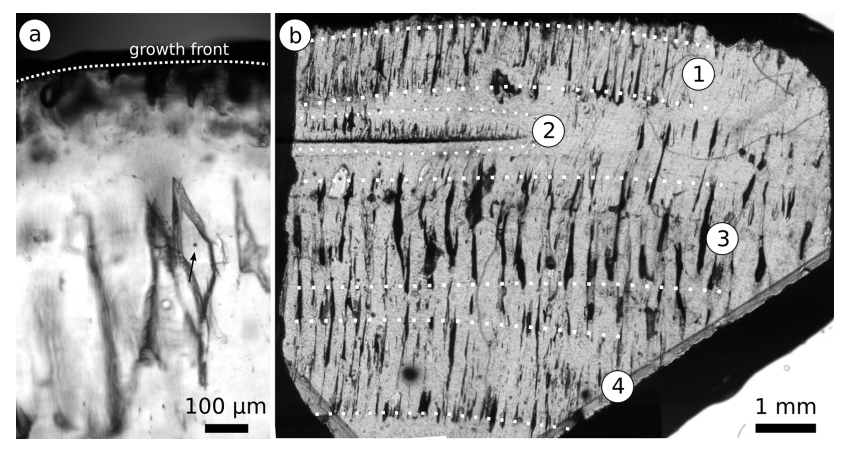

Figure 2. (a) Top of stalagmite M1 with the (active) growth front marked by the dotted line. The photograph was taken after the generation of the vapour bubble marked by the arrow. (b) Photograph of the thin section of the top of stalagmite M2. The dotted lines indicate the growth bands 1-4 with the fluid inclusion assemblages, with 1 being the youngest.

fluid inclusion equals the age of the calcite host at the top end of the fluid inclusion that lies closest to the stalagmite growth front.

The samples were transported, stored and handled at 8$12^{\circ} \mathrm{C}$, close to the present-day cave air temperature. In this way, we avoided large internal fluid overpressure induced at elevated temperatures, which could induce a stretching of the inclusion. Assuming the worst case, that an inclusion formed at $8^{\circ} \mathrm{C}$ reaches room temperature at some point during handling, would increase its internal pressure by a maximum of only 35.7 bar. 
The stalagmites were prepared to sections of $300-400 \mu \mathrm{m}$ thickness using a Buehler Isomet low speed circular saw. To avoid additional stress on the calcite host we refrained from polishing the sample surface, and used instead immersion oil to compensate for the rough surface for microscopic observation of the vapour bubble.

\subsection{Microthermometry}

For the microthermometric measurements, we used a THMSG 600 heating-freezing stage with an accuracy of $\pm 0.1^{\circ} \mathrm{C}$ (Linkam) mounted on an Olympus BX51 upright microscope. The stage was calibrated using synthetic $\mathrm{H}_{2} \mathrm{O}$ and $\mathrm{H}_{2} \mathrm{O}-\mathrm{CO}_{2}$ inclusions. The microscope was equipped with an Olympus $100 \times$ LMPlan FI LWD objective with a numerical aperture of 0.8 and an LWD condenser front lens (Linkam) with a numerical aperture of about 0.4 , resulting in a theoretical resolution of $0.4 \mu \mathrm{m}$.

The beam of a Ti:sapphire laser system (Coherent RegA 9000) delivering amplified femtosecond laser pulses was guided through the objective of the microscope to induce vapour bubble nucleation in metastable monophase inclusions (Krüger et al., 2007). Repeated measurements of $T_{\mathrm{h}}$ obs typically revealed a repeatability within $\pm 0.05^{\circ} \mathrm{C}$, indicating that the high-intensity laser pulses do not alter the volume of the inclusions. Only in the cases when the inclusion leaked did we observe a slow increase of $T_{\mathrm{h} \text { obs }}$ when we repeated the measurements with a time interval of about $24 \mathrm{~h}$.

\subsection{Bubble radius determination}

A Monte Carlo ray tracing simulation was specifically developed to model bubble imaging of optical systems with varying objective numerical aperture, condenser numerical aperture, image sensor pixel size and refractive index of the host material. The simulation models a light source, which emits a predefined number of rays according to the specified condenser parameters. Light rays are treated as vectors, and once an intersection point with the bubble boundary surface (modelled as a perfect sphere) is encountered, reflective and refractive behaviour is determined according to the Fresnel equations using pseudo-random numbers. Once the ray has passed the bubble, it is projected onto a screen.

The simulation allowed us to model situations when only a limited number of rays were considered, for example, only those that get reflected off the bubble surface. These simulations provided a fundamental understanding of how an image is formed in a microscopic system and how the image pattern is influenced by the different classes of rays.

Contrast and resolution of bubble images depend on the numerical aperture of the imaging optics used in the microscopy system. Highly resolving systems (objective with $\mathrm{NA}=1.4$ ) image a bubble having a bright centre and a bright, sharply defined circular rim that is best visible if the focus is set close to the axial centre of the bubble (see Fig. 3a). This
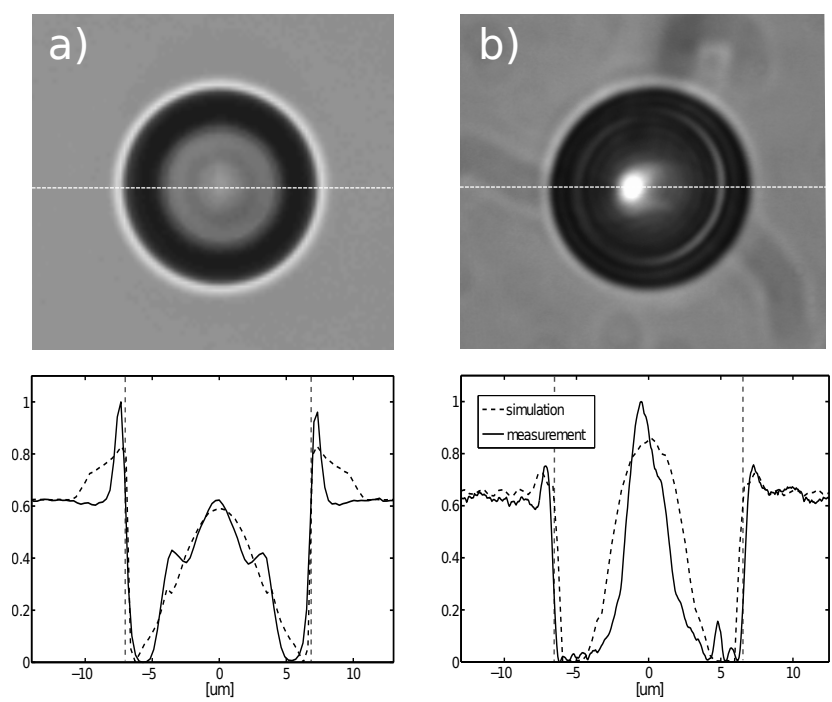

Figure 3. Comparison of two optical images of the same bubble seen through different imaging systems and their measured and simulated profiles along the dotted line shown in the images. (a) Objective NA 1.4 and condenser NA 0.4 , (b) objective NA 0.8 and condenser NA 0.2 . The outer rim is visible in both images and profiles, but much less pronounced in the low NA image on the right. The optically determined radii, (a) 6.75 and (b) $6.9 \mu \mathrm{m}$, are highlighted as vertical dashed lines in the profiles.

circular bright ring is less pronounced and with a blurred outline the lower the numerical aperture of the objective and therefore the resolution of the microscope. This fact was found independent of the focus position (Fig. 3b). To measure the bubble radius from such images accurately, one must thoroughly understand the process of image formation and its dependence on the specifications of the imaging system.

For a known imaging system, a model image (or radial profile) of a bubble of specified size can be simulated. The model is then fitted to the real optical images taken with this system, allowing a precise and consistent determination of bubble radii.

The aforementioned image simulation was verified using a non-optical measurement. Bubbles were first created inside a liquid, highly viscous epoxy resin using single femtosecond laser pulses and then cured, thus making them invariable in size. These epoxy bubbles were then imaged and analysed using the routine described above. Subsequently, the epoxy sample was cut with a microtome into $500 \mathrm{~nm}$ thick slices and measured with an atomic force microscope (AFM). The bubble radius was determined from the obtained data and compared with the prior taken optical image measurements.

The mechanically measured radii and the optical measurements turned out to deviate by no more than $\pm 0.25 \mu \mathrm{m}$, which corresponds to the lateral optical resolution of $0.24 \mu \mathrm{m}$ achieved with the high numerical aperture objective $(\mathrm{NA}=1.4)$. Said deviations also incorporated errors introduced by the AFM measurement, the microtome cutting 


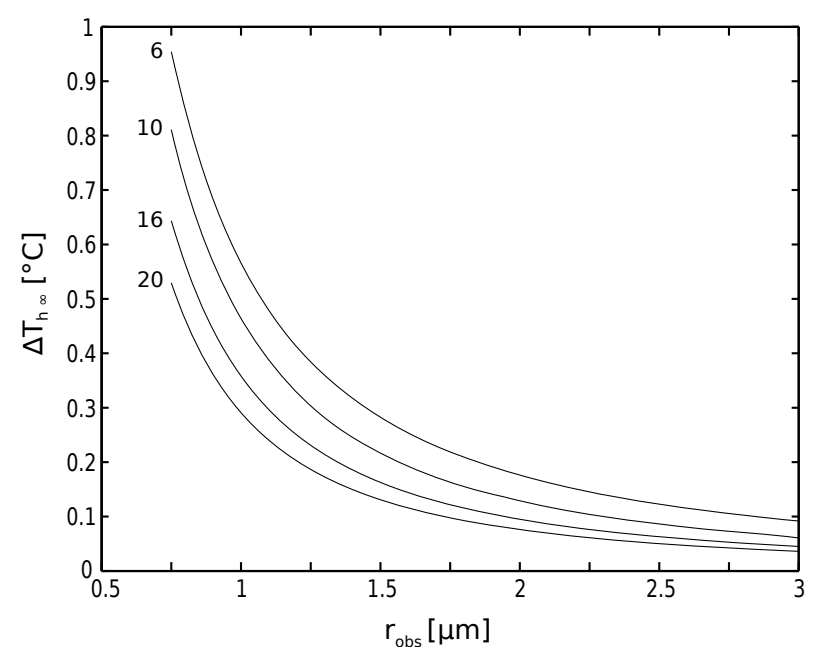

Figure 4. Error limit in $T_{\mathrm{h} \infty}$ due to an underestimation of the radius by $0.25 \mu \mathrm{m}$, as a function of the bubble radius for different $T_{\mathrm{h} \text { obs }}$ of $6,10,16$ and $20^{\circ} \mathrm{C}$.

and the reconstruction of the bubble, so the actual deviation of the optical method is most likely lower. Nevertheless, we consider this deviation to be the limit of error for our bubble radius measurement. Even the blurred images taken with a low-resolution microscope (numerical aperture of the objective NA $=0.8$ ) did not cause larger deviations despite offering significantly worse resolution, showing the robustness of our fit routine. The fit routine only failed if the resolution of the image was further reduced by spherical aberration or birefringence in the calcite, or when imaging an inclusion deep below the sample surface.

\section{Results}

\subsection{Expected error in determination of $T_{\mathrm{h} \infty}$}

Figure 4 shows the error limit $\Delta T_{\mathrm{h} \infty}$ as a function of the bubble radius for different $T_{\mathrm{h} \text { obs }}$, calculated from the thermodynamic model (Marti et al., 2012) assuming a determined radius underestimation (error) of $0.25 \mu \mathrm{m}$.

It can be seen that the larger the bubble radius and the higher $T_{\mathrm{hobs}}$ (translating to larger inclusions and higher $T_{\mathrm{h} \infty}$ ), the smaller the influence of a radius measurement error. The influence of a radius underestimation that leads to an overestimation of $T_{\mathrm{h} \infty}$ is always larger than that of an overestimation of the radius, leading to an underestimation of $T_{\mathrm{h} \infty}$.

To give an example: a bubble radius of $1.5 \mu \mathrm{m}$ at $5.1^{\circ} \mathrm{C}$ and a $T_{\mathrm{h}}$ obs of $10^{\circ} \mathrm{C}$ was measured in a fluid inclusion. Evaluation with the thermodynamic model results in an inclusion volume of $V=5.3 \times 10^{4} \mu \mathrm{m}^{3}$ and $T_{\mathrm{h} \infty}=11.55^{\circ} \mathrm{C}$. If the bubble radius is overestimated by $0.25 \mu \mathrm{m}$, i.e. the bubble radius measurement incorrectly yielded $1.75 \mu \mathrm{m}$, the $T_{\mathrm{h} \infty}$ would be underestimated by $0.16^{\circ} \mathrm{C}$, and the calculated vol-

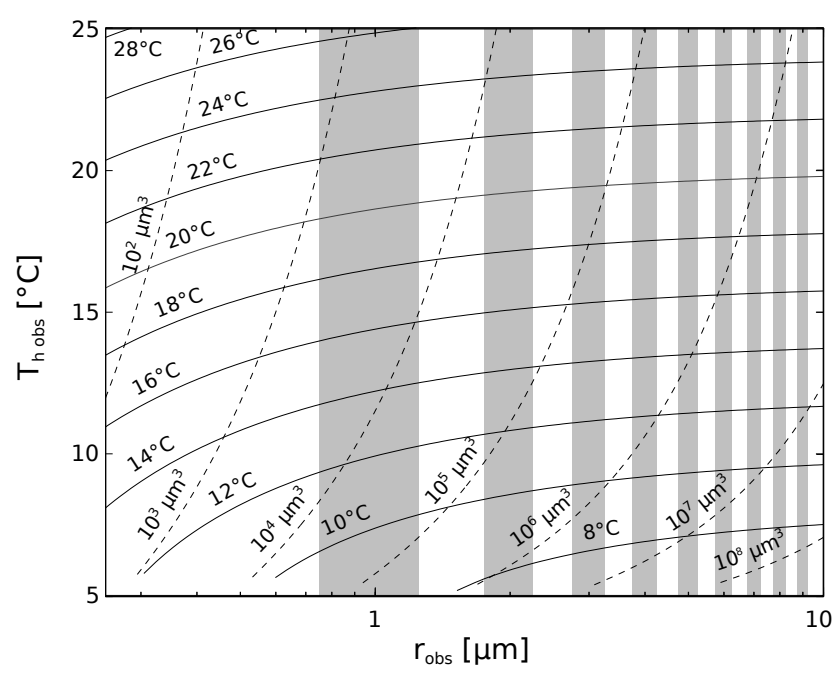

Figure 5. Dependence of the inclusion volume (dashed lines) and $T_{\mathrm{h} \infty}$ (solid lines) on $T_{\mathrm{h} \text { obs }}$ and $r_{\mathrm{obs}}$. Grey bars indicate a radius measurement error of $\pm 0.25 \mu \mathrm{m}$.

ume would be overestimated to be $8.98 \times 10^{4} \mu \mathrm{m}^{3}$. An underestimation of the radius by the same amount would lead to an overestimation of $T_{\mathrm{h} \infty}$ by $0.22^{\circ} \mathrm{C}$, and the volume would be calculated to be $3.13 \times 10^{4} \mu \mathrm{m}^{3}$.

Figure 5 shows the interrelationship between the fluid inclusion volume and formation temperature, and the observables $T_{\mathrm{h} \text { obs }}$ and $r_{\mathrm{obs}}$, the bubble radius measured at $5.1^{\circ} \mathrm{C}$. It is again apparent that the larger the inclusion volume, the smaller the effect of a radius measurement error on $T_{\mathrm{h} \infty}$.

This means that, since for the same $T_{\mathrm{h} \infty}$ larger inclusions result in larger bubble radii at $5.1^{\circ} \mathrm{C}$, only inclusions that are larger than a certain threshold can be evaluated so that the requested precision in $T_{\mathrm{h} \infty}$ is accomplished. This threshold depends on the microscope system and the formation temperature of the inclusions.

\subsection{Experimental validation on recent fluid inclusions}

To validate our theoretical assumptions, we analysed recent inclusions found in the very top layer of stalagmite M1. Since we have a good estimate of the formation temperature based on the actual cave temperature and the temperature record measured above the cave (see next paragraph) and therefore the bulk density @f of these inclusions, it is apparent from Eq. (2) that only one radius measurement is necessary to fully characterise the inclusions and calculate the theoretical radius of the vapour bubble at $5.1^{\circ} \mathrm{C}$. The easiest way to perform this measurement is when the bubble vanishes $(r=0)$, i.e. at the bubble collapse $T_{\mathrm{h} \text { obs }}$.

We selected a fluid inclusion of small volume from Stalagmite M1 (see Fig. 2a) that most likely had preserved its original fluid density, i.e. that could resist the mechanical stress induced by sample preparation. Assuming a growth rate of 


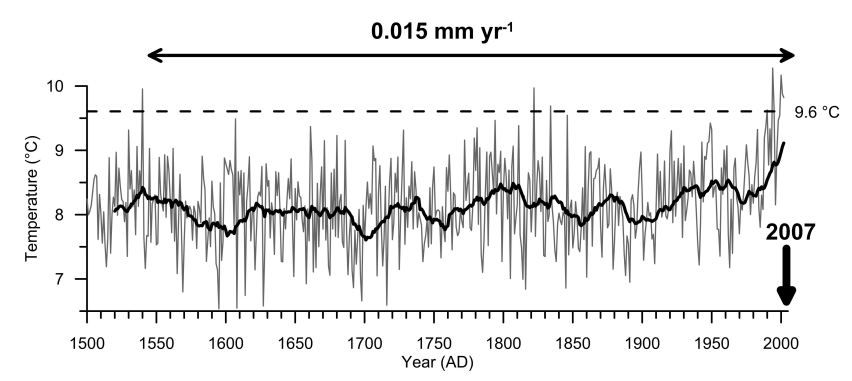

Figure 6. Surface temperature reconstruction $\left(47-48^{\circ} \mathrm{N} ; 6.5-\right.$ $7.5^{\circ} \mathrm{E}$; Luterbacher et al., 2004). The grey graph shows the annual temperatures, a $20 \mathrm{yr}$ running average is plotted in black. The current cave temperature is shown as a dashed line. The black horizontal arrow denotes the estimated temporal coverage of the studied $6 \mathrm{~mm}$ long section of stalagmite M2 assuming an average growth rate of $0.015 \mathrm{~mm}$ per year. The vertical black arrow denotes the age of the top (date of sampling) of stalagmite M2.
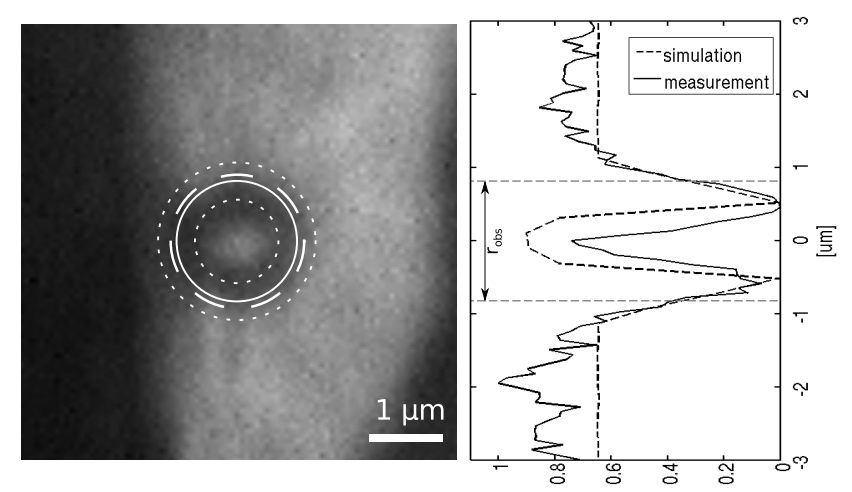

Figure 7. Photomicrograph of a vapour bubble taken at $5.1^{\circ} \mathrm{C}$ in a fluid inclusion from M1. The solid circle indicates the measured bubble size $r_{\mathrm{obs}}$, together with its margins of error $( \pm 0.25 \mu \mathrm{m}$, dotted lines). The circumference corresponding to the theoretical radius $r_{\text {calc }}$ is shown as a white dashed circle. The right side shows the measured radial intensity profile compared with the simulation as well as the physical bubble boundary $r_{\text {obs }}$.

around $15 \mu \mathrm{m}$ per year, which is comparable to that determined for stalagmite M2, the inclusion would have sealed off about $10 \mathrm{yr}$ before the stalagmite M1 was taken from the cave in 2007.

Figure 6 shows the surface temperature in the vicinity (for grid box $47-48^{\circ} \mathrm{N} ; 6.5-7.5^{\circ} \mathrm{E}$ ) of the Milandre cave between 1500 and 2002 (Luterbacher et al., 2004). A $20 \mathrm{yr}$ running average is believed to approximate the cave temperature, leading to an estimated formation temperature for the recent inclusions of $\mathrm{M} 1$ of $9.6 \pm 0.15^{\circ} \mathrm{C}$, which agrees well with the actual temperature of the cave $\left(9.59 \pm 0.15^{\circ} \mathrm{C}\right)$ measured during 2008.

Knowledge of $T_{\mathrm{f}}$ allows us to calculate a theoretical bubble radius $r_{\text {calc }}$, but for now we ignore this knowledge and try to calculate $T_{\mathrm{f}}$ based on measurements of $r_{\mathrm{obs}}$ and $T_{\mathrm{hobs}}$.
Figure 7 shows a photomicrograph of a vapour bubble taken at $5.1^{\circ} \mathrm{C}$ inside a fluid inclusion from stalagmite M1. Superimposed on the original image are the measured radius obtained from the optical bubble image with the radii corresponding to an assumed error limit of $\pm 0.25 \mu \mathrm{m}$. For comparison, the theoretical bubble radius calculated from the thermodynamic model by assuming a $T_{\mathrm{f}}$ of $9.6^{\circ} \mathrm{C}$, as derived from Fig. 6 is shown.

The radius determined from this image by fitting a simulated profile (solid circle in Fig. 7) was $0.82 \pm 0.25 \mu \mathrm{m}$, which is $0.09 \mu \mathrm{m}$ smaller than the theoretical radius. Together with the measured $T_{\mathrm{hobs}}$ of $6.5^{\circ} \mathrm{C}$, this results in $T_{\mathrm{h} \infty}$ of $9.87 \pm 0.80^{\circ} \mathrm{C}$, which is $0.27^{\circ} \mathrm{C}$ higher than the estimated formation temperature.

It is remarkable that despite the very small bubble and lowresolution image, making it all but impossible to determine an accurate bubble radius, our method enables us to determine temperature data that are in good agreement with estimations based on the air temperature measurements above the cave, which match the actual recorded cave temperature. This is testimony to the robustness and consistency of our method.

\subsection{Determination of paleotemperatures}

After testing our method on a fluid inclusion of known formation temperature, we determined the nominal homogenisation temperature $T_{\mathrm{h} \infty}$ of different fluid inclusion assemblages found within the top 6-7 mm of stalagmite M2.

Assuming an average growth rate of $0.015 \mathrm{~mm}$ per year (see Sect. 3.1 for further details), the top 6-7 mm could comprise the last $450 \mathrm{yr}$ or even less if the growth rate was slightly higher. As mentioned earlier, this section contains four major growth bands with numerous fluid inclusions (see Fig. 2b). Outside the Milandre cave, the mean annual temperature has varied during the last $450 \mathrm{yr}$ as shown in Fig. 6 (Luterbacher et al., 2004). It can be seen that the mean annual temperature varied around $8.4^{\circ} \mathrm{C}$ (smoothed values) with a strong increase during the last $50 \mathrm{yr}$ to the actual value of $9.6^{\circ} \mathrm{C}$, which matches the actual recorded cave temperature. If we assume that the cave climate reacts slowly to changes in surface temperature, these data show that the cave temperature varied in the same range. Figure 8 shows the calculated $T_{\mathrm{h} \infty}$ of fluid inclusions from the stalagmite $\mathrm{M} 2$ as a function of the inclusion volume, calculated from $r\left(5.1^{\circ} \mathrm{C}\right)$ and $T_{\mathrm{h} \text { obs }}$ measurements. Each $T_{\mathrm{h} \infty}$ value represents the formation temperature of the respective inclusion at the time it was sealed off from the environment.

\section{Discussion}

We aimed to determine the accuracy with which our model allows us to determine the nominal homogenisation temperature $T_{\mathrm{h} \infty}$ of a single fluid inclusion. We introduced a simulation-based measurement method of bubble radii for 


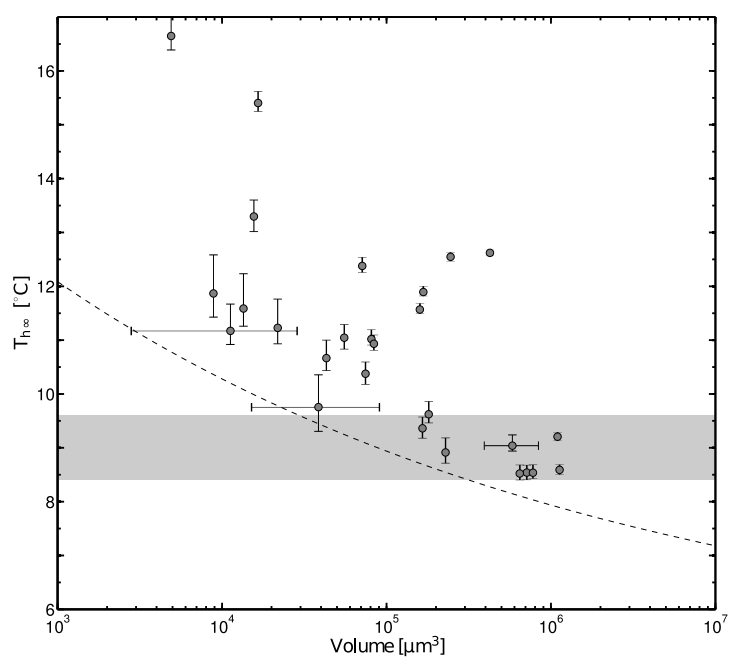

Figure 8. Results from stalagmite $\mathrm{M} 2 . T_{\mathrm{h}} \infty$ and inclusion volumes are calculated from $T_{\mathrm{h} \text { obs }}$ and $r\left(5.1^{\circ} \mathrm{C}\right)$ and are shown as grey dots. The errors in $T_{\mathrm{h} \infty}$ and the inclusion volume $V$ resulting from an error in bubble radius determination of $\pm 0.25 \mu \mathrm{m}$ are indicated. For the sake of legibility, not all volume error bars are shown. See Fig. 4 for a more complete illustration of the errors. The expected formation temperature of the analysed stalagmite section is indicated by the grey bar. The dashed curve depicts the boundary below which no bubble can be nucleated, for details refer to Sect. 5 .

which we established a maximum deviation of no more than $\pm 0.25 \mu \mathrm{m}$.

In Fig. 4, we showed how this radius measurement error limit of $\pm 0.25 \mu \mathrm{m}$ affects the precision of the calculated $T_{\mathrm{h} \infty}$ for different values of $T_{\mathrm{h} \text { obs. }}$. It can be seen that for inclusions with a high $T_{\mathrm{h}}$ obs and bubble radii above $1.5 \mu \mathrm{m}$, the resulting error in $T_{\mathrm{h} \infty}$ remains smaller than $\pm 0.25^{\circ} \mathrm{C}$. It can also be seen that, again assuming a radius measurement error limit of $\pm 0.25 \mu \mathrm{m}$, even for low $T_{\mathrm{h} \text { obs }}$ and radii as small as $0.75 \mu \mathrm{m}$, the error in $T_{\mathrm{h} \infty}$ determination is still smaller than $\pm 1^{\circ} \mathrm{C}$, a significant improvement over alternative techniques.

Figure 7 shows the above principle in an inclusion of stalagmite M1, where the formation temperature and, therefore, $T_{\mathrm{h} \infty}$ is known. We compared the measured bubble radius with the theoretical radius calculated from the known formation temperature. The image shows a bubble inside a small inclusion of a volume of $5.0 \times 10^{4} \mu^{3}$. Despite the fact that the radius of the bubble is measured to be only $0.82 \mu \mathrm{m}$ and a microscope with a low NA-objective $(\mathrm{NA}=0.8)$ was used, leading to a blurred image whose quality is additionally reduced by birefringent effects of the calcite, the measured size of the bubble and the theoretically calculated size nicely agree. The measured radius was apparently underestimated by $0.09 \mu \mathrm{m}$, which translates into an error in the formation temperature of $+0.27^{\circ} \mathrm{C}$ compared to the current, measured cave temperature.

When analysing inclusions and inclusion assemblages in stalagmites, we are faced with an additional source of error: the inclusions may have leaked due to cracks in the host calcite, incorrect storage or handling or measurement preparation steps such as sawing. We can still determine $T_{\mathrm{h}} \infty$ of such inclusions with high precision, but it may no longer equal the formation temperature $T_{\mathrm{f}}$. We are not aware of any mechanism that lowers $T_{\mathrm{h} \infty}$ of an inclusion. Therefore, we assume that all mechanisms altering the inclusion will result in a $T_{\mathrm{h} \infty}$ that is higher than the formation temperature $T_{\mathrm{f}}$. The closest approximation of the stalagmite formation temperature is derived from inclusions that display the lowest $T_{\mathrm{h} \infty}$ values within individual growth bands, assuming that a number of unaltered inclusions are present in each growth band. The temporal resolution of our technique therefore depends on the number of inclusions found in a given growth band since we now rely on statistics.

The outcome of such a measurement of fluid inclusions in stalagmite M2 is shown in Fig. 8. These inclusions were found in the growth bands 1-4 (see Fig. 2), which were formed over a period of about $450 \mathrm{yr}$ (Fig. 6), during which the cave air temperature increased by about $1.2^{\circ} \mathrm{C}$ to the actual cave temperature of $9.6^{\circ} \mathrm{C}$. As a result, the formation temperatures of the inclusions range from 8.4 to $9.6^{\circ} \mathrm{C}$, shown as a grey band in Fig. 8. The low temporal resolution of $450 \mathrm{yr}$ is a result of the fact that we had to break our samples into small pieces of maximum $7 \mathrm{~mm}$ in diameter due to the limited space of the heating/freezing stage used. After breaking the samples, we were no longer able to precisely determine the exact position of the fluid inclusion. Therefore, a chronological reconstruction of the temperature data within the last $450 \mathrm{yr}$ was not possible. In future, an exact positioning of the inclusion will be possible due to our novel freezing/heating stage which allows us to study large samples (Krüger et al., 2014).

The data reveal that there appears to be a trend towards lower $T_{\mathrm{h} \infty}$ with increasing inclusion volume. This trend, however, can be attributed to the surface tension: the smaller the inclusions, the smaller the bubbles inside the inclusions, and the larger the influence of the surface tension. For each specific $T_{\mathrm{h} \infty}$, there is an inclusion volume below which no bubble can be induced, since the surface tension is strong enough to prohibit bubble nucleation (Marti et al., 2012). In Fig. 8, this threshold is shown as a dotted line. For the presented data from the Milandre cave, where $T_{\mathrm{f}}$ lies between 8.4 and $9.6^{\circ} \mathrm{C}$, the smallest volumes where a bubble can still be nucleated are between about $3 \times 10^{5}$ and $3 \times 10^{4} \mu \mathrm{m}^{3}$, respectively. For inclusions below these sizes, it is impossible to nucleate a bubble unless the inclusion has leaked. Thus, since we rely on bubble radius determination in our method, we are not able to measure $T_{\mathrm{h} \infty}$ of unaltered inclusions that are smaller in volume than this threshold.

In the case of the Milandre cave, the calculated $T_{\mathrm{h} \infty}$ of the lowest $30 \%$ (8 out of 27) inclusions lie within the band that depicts the possible formation temperatures; these $30 \%$ can be assumed not to have leaked and, thus, to show the correct formation temperature. In fact, in older stalagmites 
(hundreds of thousand of years), where the host calcite had time to recrystallise, there is a clear gap observable between low $T_{\mathrm{h} \infty}$ and high $T_{\mathrm{h} \infty}$ of inclusions. We assume these low $T_{\mathrm{h} \infty}$ inclusions to have kept their original density and the high $T_{\mathrm{h} \infty}$ inclusions to have leaked over time (Meckler et al., 2015).

For growth bands with few inclusions, our method can therefore only provide an upper limit to the temperature. The higher the number of inclusions within a growth band, the more precise this upper limit coincides with the formation temperature. The same is true for inclusions in less porous hosts, as this decreases the percentage of inclusions that are altered during preparation.

We can therefore conclude that, when measuring fluid inclusion assemblages in stalagmites of unknown formation temperature, we can apply the method described in Marti et al. (2012) to determine $T_{\mathrm{h} \infty}$ of the inclusions. To determine the formation temperature and, therefore, the cave air temperature at the time the inclusion assemblage was formed, we then have to consider only the lowest values of the calculated $T_{\mathrm{h} \infty}$. The size of the measured inclusions however limits the possible formation temperatures accessible, due to the aforementioned volume threshold. Nonetheless, if enough large inclusions are present, the method presented can achieve an accuracy in cave air temperature determination of $\pm 0.25^{\circ} \mathrm{C}$.

\section{Conclusions}

We introduced a simulation-based bubble radius determination method and successfully assessed its accuracy by comparing it to non-optical measurements. We revealed that in conjunction with this method, our thermodynamic model enables us to reliably determine the nominal homogenisation temperature of single inclusions with an accuracy of better than $\pm 0.25^{\circ} \mathrm{C}$ if the vapour bubble radius exceeds $1.5 \mu \mathrm{m}$. For smaller radii, $\Delta T_{\mathrm{h} \infty}$ will be no larger than $\pm 1^{\circ} \mathrm{C}$. The success of our method in determining paleotemperatures depends on the number of fluid inclusions that can be found in a growth band of the stalagmite. For high enough numbers, our method allows accurate determination of cave temperatures with an error no worse than $\pm 1^{\circ} \mathrm{C}$. If in addition the stalagmite contains large inclusions, the precision expected is even better than $\pm 0.25^{\circ} \mathrm{C}$.

Acknowledgements. This work was supported in part by the Swiss National Foundation SNF Sinergia "Stalclim" (SNF grant: CSRI22-132646/1). The authors acknowledge the great support of Silvia Schmassmann, Pierre-Yves Jeannin and Philip Häuselmann, Swiss Institute of Speleology and Karst Studies (SISKA). We would additionally like to thank Michael Stoffel and Véronique Gaschen for the preparation of the epoxy bubble slices and Yves Krüger for helpful discussions.

Edited by: E. Brook

\section{References}

Affek, H. P., Bar-Matthews, M., Ayalon, A., Matthews, A., and Eiler, J. M.: Glacial/interglacial temperature variations in Soreq cave speleothems as recorded by "clumped isotope" thermometry, Geochim. Cosmochim. Ac., 72, 5351-5360, doi:10.1016/j.gca.2008.06.031, 2008.

Fairchild, I. J. and Treble, P.: Trace elements in speleothems as recorders of environmental change, Quaternary Sci. Rev., 28, 449-468, 2009.

Fairchild, I. J., Smith, C. L., Baker, A., Fuller, L., Spotl, C., Mattey, D., and McDermott, F.: Modification and preservation of environmental signals in speleothems, Earth-Sci. Rev., 75, 105153, doi:10.1016/j.earscirev.2005.08.003, 2006.

Fall, A., Rimstidt, J., and Bodnar, R.: The effect of fluid inclusion size on determination of homogenization temperature and density of liquid-rich aqueous inclusions, Am. Mineral., 94, 15691579, 2009.

Ghosh, P., Adkins, J., Affek, H., Balta, B., Guo, W., Schauble, E. A., Schrag, D., and Eiler, J. M.: ${ }^{13} \mathrm{C}-{ }^{18} \mathrm{O}$ bonds in carbonate minerals: a new kind of paleothermometer, Geochim. Cosmochim. Ac., 70, 1439-1456, doi:10.1016/j.gca.2005.11.014, 2006.

Häuselmann, A., Fleitmann, D., Affolter, S., Cheng, H., Edwards, L. R., and Leuenberger, M.: Nature and timing of the last deglaciation recorded in stalagmites from Milandre Cave in Switzerland, Quaternary Sci. Rev., in preparation, 2015.

Kendall, A. and Broughton, P.: Origin of fabrics in speleothems composed of columnar calcite crystals, J. Sediment. Res., 48, 519-538, 1978.

Kluge, T., Marx, T., Scholz, D., Niggemann, S., Mangini, A., and Aeschbach-Hertig, W.: A new tool for palaeoclimate reconstruction: noble gas temperatures from fluid inclusions in speleothems, Earth Planet. Sc. Lett., 269, 408-415, doi:10.1016/j.eps1.2008.02.030, 2008.

Krüger, Y., Stoller, P., Ricka, J., and Frenz, M.: Femtosecond lasers in fluid-inclusion analysis: overcoming metastable phase states, Eur. J. Mineral., 19, 693-706, 2007.

Krüger, Y., Marti, D., Hidalgo Staub, R., Fleitmann, D., and Frenz, M.: Liquid-vapour homogenisation of fluid inclusions in stalagmites: evaluation of a new thermometer for paleoclimate research, Chem. Geol., 5, 39-47, 2011.

Krüger, Y., Hiltbrunner, B., Luder, A., Fleitmann, D., and Frenz, M.: Novel heating/cooling stage designed for fluid inclusion microthermometry of large stalagmite sections, Chem. Geol., 386, 59-65, 2014.

Luterbacher, J., Dietrich, D., Xoplaki, E., Grosjean, M., and Wanner, H.: European seasonal and annual temperature variability, trends, and extremes since 1500, Science, 303, 1499-1503, 2004.

Marti, D., Krüger, Y., and Frenz, M.: Fluid inclusion liquid-vapour homogenisation in the vicinity of the density maximum of aequous solutions, Proceedings of ECROFI XX, European Current Research on Fluid Inclusions, Granada, 2009.

Marti, D., Krüger, Y., Fleitmann, D., Frenz, M., and Ricka, J.: The effect of surface tension on liquid-gas equilibria in isochoric systems and its application to fluid inclusions, Fluid Phase Equilibr., 314, 13-21, 2012.

McDermott, F.: Palaeo-climate reconstruction from stable isotope variations in speleothems: a review, Quaternary Sci. Rev., 23, 901-918, doi:10.1016/j.quascirev.2003.06.021, 2004. 
McGarry, S., Bar-Matthews, M., Matthews, A., Vaks, A., Schilman, B., and Ayalon, A.: Constraints on hydrological and paleotemperature variations in the Eastern Mediterranean region in the last $140 \mathrm{ka}$ given by the $\delta D$ values of speleothem fluid inclusions, Quaternary Sci. Rev., 23, 919-934, doi:10.1016/j.quascirev.2003.06.020, 2004.

Meckler, A. N., Affolter, S., Dublyansky, Y., Krüger, Y., Vogel, N., Bernasconi, S., Frenz, M., Kipfer, R., Leuenberger, M., Spötl, C., Carolin, S., Cobb, K., Moerman, J., Adkins, J., and Fleitmann, D.: Glacial-interglacial temperature change in the tropical West Pacific: A comparison of stalagmite-based paleothermometers, Quaternary Sci. Rev., in press, 2015.

Rao, K., Naidu, S., and Murthy, K.: Precision lattice parameters and thermal expansion of calcite, J. Phys. Chem. Solids, 29, 245-248, 1968.

Scheidegger, Y., Baur, H., Brennwald, M. S., Fleitmann, D., Wieler, R., and Kipfer, R.: Accurate analysis of noble gas concentrations in small water samples and its application to fluid inclusions in stalagmites, Chem. Geol., 272, 31-39, doi:10.1016/j.chemgeo.2010.01.010, 2010.
Schmassmann, S.: Speleothem-Based Climate and Environmental Reconstruction: a Pilot Study in the Swiss Jura Mountains, Master's thesis, University of Bern, Bern, 2010.

Wagner, W. and Pruss, A.: The IAPWS formulation 1995 for the thermodynamic properties of ordinary water substance for general and scientific use, J. Phys. Chem. Ref. Data, 31, 387-535, 2002.

Zhang, R., Schwarcz, H. P., Ford, D. C., Schroeder, F. S., and Beddows, P. A.: An absolute paleotemperature record from 10 to 6 $\mathrm{ka}$ inferred from fluid inclusion $\mathrm{D} / \mathrm{H}$ ratios of a stalagmite from Vancouver Island, British Columbia, Canada, Geochim. Cosmochim. Ac., 72, 1014-1026, doi:10.1016/j.gca.2007.12.002, 2008. 